\title{
Identification of the ventricular tachycardia circuit using the Advisor HD Grid multielectrode mapping catheter
}

\author{
Aleksander Maciąg, Michał Farkowski, Mariusz Pytkowski \\ 2nd Department of Heart Arrhythmia, National Institute of Cardiology, Warsaw, Poland
}

Correspondence to: Aleksander Maciąg, MD, PhD, 2nd Department of Heart Arrhythmia, National Institute of Cardiology, ul. Alpejska 42, 04-628 Warszawa, Poland, phone: +48223434049 , email: amaciag@ikard.pl Received: May 3, 2020. Revision accepted: June 1, 2020 Published online: June 5, 2020. Kardiol Pol. 2020; 78 (9): 928-929 doi:10.33963/KP.15423 Copyright by the Author(s), 2020
One of 2 main strategies for dealing with life-threating arrhythmias represents mapping and ablation of the ventricular tachycardia (VT) circuit. ${ }^{1}$ High-density mapping of the left ventricle using a dedicated multipolar catheter can provide a unique insight into both arrhythmia substrate and VT circuit. ${ }^{2,3}$ The construction of the Advisor HD grid catheter (Abbott Medical, Abbott Park, Illinois, United States) allows for a highly detailed bipolar recording of myocardial electrical activity, which cannot be emulated when using standard mapping and ablation catheters. ${ }^{4}$

A 72-year-old man with a history of myocardial infarction, implantable cardioverter-defibrillator, and recurrent VT was scheduled for radiofrequency ablation. In the electrophysiology laboratory, arrhythmia was easily induced and well tolerated by the patient.

Then, we mapped the VT circuit using the Advisor HD grid catheter and the EnSite

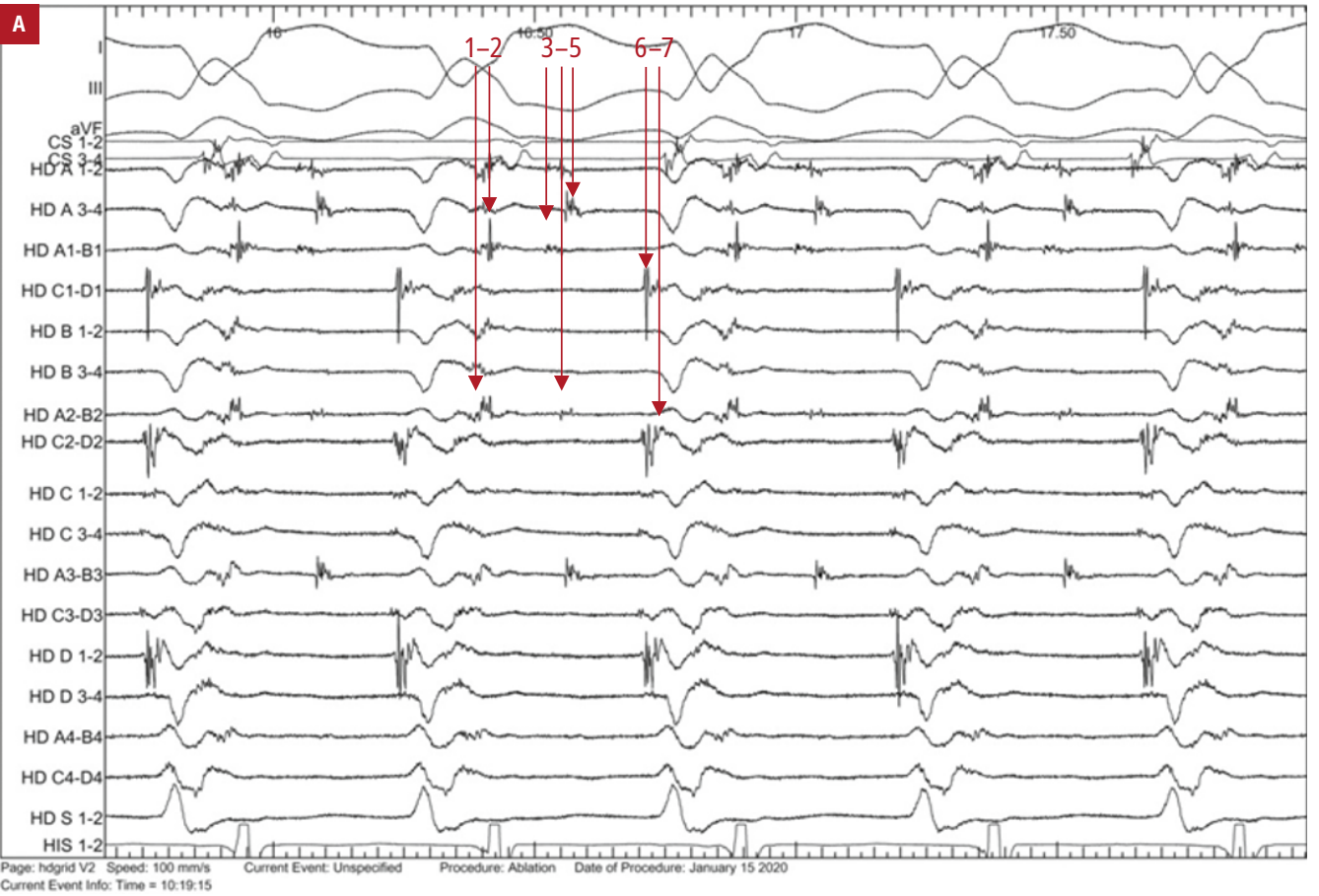

FIGURE 1 A - multicomponent, low-amplitude intracardiac electrocardiograms recorded by the Advisor HD Grid catheter, covering the whole ventricular tachycardia cycle (arrows) 
FIGURE 1 B - a voltage map of the left ventricular lateral wall showing multiple fractionated potentials marked by white-yellow dots, recorded in the low-amplitude area (voltage below $0.5 \mathrm{mV}$, coded in grey) and corresponding to the infarcted area; $\mathbf{C}$ - an activation map of the left ventricular lateral wall showing the area of slow conduction within low-amplitude regions. The estimated Advisor HD Grid catheter position is marked with a rectangle. The arrows (B and $\mathbf{C}$ ) indicate the ablation site that terminated ongoing ventricular tachycardia.

Precision electroanatomical mapping system (Abbott Medical). On the lateral wall of the left ventricle, we recorded multicomponent, low-amplitude intracardiac electrocardiograms covering the full VT cycle (FIGURE 1A). Most of them were recorded in a low-amplitude area (below $0.5 \mathrm{mV}$ ) corresponding to the infarcted area. These points marked by white-yellow dots were clearly visible amid the low-amplitude area color coded in grey (FIGURE 1B). In the EnSite Precision system, it was possible to mark points with multicomponent potential (3 or more components in this case) independently of the potential amplitude. On activation maps, tightly arranged isochrones showed the area of slow activation within the low-amplitude area (FIGURE 1C). Pacing from the consecutive bipoles of the catheter captured each recorded component and propagation of VT (Supplementary material, Video S1). Entrainment mapping confirmed the identification of the critical isthmus by demonstrating both concealed fusion and a perfect postpacing interval (Supplementary material, Figure S1). Ablation performed at this site (FIGURE $1 \mathrm{~B}$ and $1 \mathrm{C}$ ) successfully terminated VT (Supplementary material, Figure S2).

Recently introduced multielectrode catheters allow for high-density mapping and provide an extraordinary possibility to identify VT circuit components. Finally, modern multielectrode catheters enable us to easily merge multiple VT mapping techniques including activation mapping, substrate mapping, entrainment, and analysis of fractionated potentials in order to better understand the VT substrate and improve ablation outcomes. ${ }^{1-4}$

\section{ARTICLE INFORMATION}

CONFLICT OF INTEREST AM, MF, and MP received speaker and proctoring honoraria from Abbott Medical Poland.

OPEN ACCESS This is an Open Access article distributed under the terms of the Creative Commons Attribution-NonCommercial-NoDerivatives 4.0 International License (CC BY-NC-ND 4.0), allowing third parties to download articles and share them with others, provided the original work is properly cited, not changed in any way, distributed under the same license, and used for noncommercial purposes only. For commercial use, please contact the journal office at kardiologiapolska@ptkardio.pl.

HOW TO CITE Maciąg A, Farkowski M, Pytkowski M. Identification of the ventricular tachycardia circuit using the Advisor HD Grid multielectrode mapping catheter. Kardiol Pol. 2020; 78: 928-929. doi:10.33963/KP.15423

\section{REFERENCES}

1 Cronin EM, Bogun FM, Maury P, et al. 2019 HRS/EHRA/APHRS/LAHRS expert consensus statement on catheter ablation of ventricular arrhythmias: executive summary. Europace. 2020; 22: 450-495.

2 Aziz Z, Shatz D, Raiman M, et al. Targeted ablation of ventricular tachycardia guided by wavefront discontinuities during sinus rhythm: a new functional substrate mapping strategy. Circulation. 2019; 140: 1383-1397.

3 Hindricks $\mathrm{G}$, Weiner $\mathrm{S}, \mathrm{McE}$ Elderry $\mathrm{T}$, et al. Acute safety, effectiveness, and real-world clinical usage of ultra-high density mapping for ablation of cardiac arrhythmias: results of the TRUE HD study. Europace. 2019; 21: 655-661.

4 Wójcik M, Konarski Ł, Aljabali P, et al. Ablation of symptomatic ventricular tachycardia after surgical correction of ventricular septal defect in childhood: using high-density mapping, how precise is EnSite Precision? Kardiol Pol. 2018; 76 : 930-930.

\section{SUPPLEMENTARY MATERIAL}

Supplementary material is available at www.mp.pl/kardiologiapolska. 